\title{
Estudo taxonômico de Abuta (Menispermaceae) no estado do Acre, Brasil
}

\author{
Taxonomic study of Abuta (Menispermaceae) in the state of Acre, Brazil
}

\author{
Julio dos Santos de Sousa ${ }^{1,4}$, Ely Simone Cajueiro Gurgel $^{2} \&$ Maria de Nazaré do Carmo Bastos $^{3}$
}

\begin{abstract}
Resumo
Um tratamento taxonômico de Abuta para o estado do Acre é apresentado. A metodologia abrangeu a análise do material proveniente de 17 coletas e amostras de exsicatas de herbários nacionais e estrangeiros, além de literatura especializada. $\mathrm{O}$ gênero está representado na área por oito espécies: Abuta barbata, A. brevifolia, A. grandifolia, A. obovata, A. pahnii, A. rufescens, A. sandwithiana e A. solimoesensis. São apresentadas chave de identificação, descrições e ilustrações das espécies, bem como dados adicionais sobre distribuição geográfica e comentários taxonômicos.
\end{abstract}

Palavras-chave: Anomospermeae, botânica, Menispermoideae, morfologia, taxonomia.

\begin{abstract}
A taxonomic treatment of Abuta in the Acre state is presented. Botanical specimens from national and foreign herbaria, as well as 17 new collections and the literature, were analyzed. The genus is represented by eight species: Abuta barbata, A. brevifolia, A. grandifolia, A. obovata, A. pahnii, A. rufescens, A. sandwithiana and $A$. solimoesensis. Identification keys, descriptions, and illustrations of the species are presented, as well as data concerning geographical distribution and additional comments of the species.
\end{abstract}

Key words: Anomospermeae, botany, Menispermoideae, morphology, taxonomy.

\section{Introdução}

Menispermaceae compreende aproximadamente 72 gêneros e cerca de 520 espécies, com distribuição essencialmente pantropical (Jacques et al. 2007; Wefferling et al. 2013). No Brasil, a família engloba 15 gêneros, 108 espécies (29 endêmicas), seis subespécies e sete variedades (BFG 2015) distribuídas em oito tribos: Menispermeae DC., Tiliacoreae Miers, Anomospermeae Miers, Coscinieae Hook.f. \& Thoms., Tinosporeae Hook.f. \& Thoms., Peniantheae Diels, Fibraureae Diels e Hyperbaeneae Diels. A tribo Anomospermeae está representada nas formações vegetais brasileiras por seis gêneros, sendo Abuta o mais representativo em número de espécies.
Apesar de a lista brasileira apresentar mais de 95,5\% nomes de angiosperma atualizados por especialistas (BFG 2015), alguns táxons de Menispermaceae, especialmente Abuta, ainda carecem de revisão.

Abuta foi descrito por Aublet e compreende cerca de 35 espécies tropicais (Di Stasi \& HirumaLima 2002; Sousa et al. 2014a). Ocorre nas florestas tropicais, do sul do México a Bolívia, sendo que no Brasil, tem maior diversidade na Amazônia (incluindo a parte extra-brasileira), Guiana, Suriname e Guiana Francesa (Barneby 2001; Sousa et al. 2014a). O gênero é facilmente reconhecido por ser o único de Anomospermeae a possuir flores monoclamídeas desprovidas de pétalas.

\footnotetext{
${ }^{1}$ Museu Paraense Emílio Goeldi - MPEG, Prog. Capacitação Institucional - PCI, Campus de Pesquisa, Coord. Botânica, Av. Perimetral 1901, Terra Firme, 66017-970, Belém, PA, Brasil.

${ }^{2}$ Museu Paraense Emílio Goeldi - MPEG, Campus de Pesquisa, Coord. Botânica, Av. Perimetral 1901, Terra Firme, 66017-970, Belém, PA, Brasil. esgurgel@ museu-goeldi.br

${ }_{3}^{3}$ Museu Paraense Emílio Goeldi - MPEG, Campus de Pesquisa, Coord. Botânica, Av. Perimetral 1901, Terra Firme, 66017-970, Belém, PA, Brasil. nazir@ museu-goeldi.br

${ }^{4}$ Autor para correspondência: jssousa27@yahoo.com.br
} 
Algumas espécies de Abuta, segundo Sothers et al. (1999), são ricas em alcalóides e as folhas, cascas, madeiras e raízes têm utilidades medicinais para várias moléstias (cólicas, malária, tuberculose, entre outras) e na preparação do curare, do qual são extraídas substâncias de ação paralisante utilizadas nas pontas das flechas para caça e pesca.

$\mathrm{Na}$ flora brasileira, especialmente para região Amazônica, estudos envolvendo as espécies de Abuta estão representados por tratamentos taxonômicos feitos em floras regionais, locais ou restritos às áreas de proteção ambiental, que geralmente incluem poucas espécies, como os de Albuquerque (1972), que tratou a nervação foliar de cinco espécies de Abuta; Sothers et al. (1999), os quais registraram sete espécies do gênero na Reserva Ducke e Sousa et al. (2014 $\mathrm{a}, \mathrm{b})$ que realizaram o estudo taxonômico de $11 \mathrm{e}$ oito espécies do gênero para os estados do Pará e Rondônia, respectivamente.

A delimitação das espécies de Abuta é bastante complexa, uma vez que as flores são unissexuadas (plantas dioicas). Muitas espécies são tratadas e/ou representadas em coleções de forma incompleta, o que dificulta a análise taxonômica para elucidar as circunscrições das mesmas.

Diante da complexa delimitação morfológica das espécies e à necessidade de estudos na área, o presente trabalho teve por objetivo realizar o tratamento taxonômico de Abuta no estado do Acre, fornecendo informações para uma melhor compreensão e identificação das espécies, contribuindo para o avanço no conhecimento do gênero na flora do Brasil.

\section{Material e Métodos}

O estudo foi baseado em material proveniente de expedições de campo e herborizado, procedente do estado do Acre, incorporado nos herbários: HERBAM, MG, MO, IAN, INPA, NY, RB, R, UB, UFACPZ (abreviaturas com base em Thiers, continuamente atualizado). Para as etapas de coleta foram adotadas as recomendações técnicas propostas por Fidalgo \& Bononi (1984). O material foi analisado, descrito e ilustrado com auxílio de lupa estereomicroscópica com câmara-clara acoplada. As descrições estão de acordo com a metodologia clássica utilizada em taxonomia vegetal, adotando-se as terminologias das partes vegetativas e reprodutivas segundo Radford et al. (1974), Hickey (1973), Rizzini (1977), Weberling (1992), Barroso et al. (1999) e Harris \& Harris (2001). A identificação das espécies foi realizada por análise dos tipos, chaves analíticas e literatura especializada, tais como Diels (1910), Krukoff \& Moldenke (1938), Krukoff \& Barneby (1970), Barneby \& Krukoff (1971).

\section{Resultados e Discussão}

Abuta Barrère ex Aubl., Hist. Pl. Guiane 1: 618, pl. 250. 1775.

Espécie-tipo: Abuta rufescens Aubl., Hist. Pl. Guiane 1: 618-620, t. 250. 1775. Tipo: GUIANA FRANCESA. Aublet s.n. (holótipo BM).

Arbustos escandentes ou lianas, dioicos. Folhas alternas, basifixas ou subpeltadas; venação acródroma ou actinódroma; nervuras principais 3-5, palmatinérveas ou plinérveas; pecíolo cilíndrico ou canaliculado, com pulvino proximal e distal. Inflorescências em bótrios, panículas, racemos simples ou racemos compostos fasciculados, multifloras, axilares, supra-axilares e/ou caulifloras. Flores monoclamídeas, actinomorfas, hipóginas; sépalas 6-9, dispostas em verticilo bisseriado ou trisseriado; pétalas ausentes. Flores estaminadas contendo 6 estames livres ou conatos; anteras com deiscência colateral, longitudinal ou transversal, bitecas. Flores pistiladas com 6 estaminódios; gineceu tricarpelar, apocárpico; ovário súpero, unilocular, com 2 óvulos por carpelo, sendo 1 abortivo; estigma subapical ou apical. Drupas solitárias ou aos pares na infrutescência; cicatriz do estigma sub-basal, epicarpo subcoriáceo a coriáceo, mesocarpo carnoso ou delgado; endocarpo em forma de "U" invertido, crustáceo ou lenhoso, externamente marcado em cada lado por uma ranhura em forma de "U" invertido, endosperma ruminado, em forma de "U" invertido; côndilo lamelar, vertical ao eixo longitudinal da semente, intrusão lateral; embrião curvado na região mediana.

Abuta é bem definido e facilmente distinguível dos demais gêneros de Anomospermeae por ser o único da tribo apétalo. Esse gênero está representado por ca. 32 espécies distribuídas desde o sul do México até a Bolívia, com cinco registros de ocorrência na Mesoamérica (Ortiz 2011). Nas formações vegetais brasileiras, ocorre nos domínios fitogeográficos da Amazônia, Caatinga, Cerrado, Mata Atlântica e Pantanal (BFG 2015). As espécies podem ser encontradas em floresta de várzea, floresta de igapó, floresta ripária, floresta de terra firme, floresta ombrófila densa, floresta estacional semidecidual, savana, campinarana, cerrado, restinga e floresta mista de transição, em condições de solos argilosos, arenosos, arenoargilosos a lateríticos. 


\section{Chave de identificação das espécies de Abuta no estado do Acre}

1. Lianas.

2. Nervuras principais 5-palmatinérveas.

3. Ritidoma vináceo; lâmina foliar hirsuta na face abaxial; brácteas falcadas ou lanceoladas, seríceas ou lanosas; ovário lanoso ou seríceo; estigma bífido, liguliforme ....... Abuta pahnii

3'. Ritidoma marrom a acinzentado; lâmina foliar cinéreo-tomentosa na face abaxial; brácteas ovaladas, tomentosas ou velutinas; ovário velutino, estigma lobado, labiado .. Abuta rufescens

2'. Nervuras principais 3-palmatinérveas ou plinérveas.

4. Lâmina foliar bulada, venação actinódroma basal.

5. Pecíolo viloso-ferrugíneo; lâmina foliar cartácea; nervuras secundárias divergindo do terço inferior laminar; brácteas lanceoladas ou oblongas; filete curvado Abuta barbata

5'. Pecíolo pubescente; lâmina foliar coriácea; nervuras secundárias divergindo da região mediana laminar; brácteas ovaladas ou cimbiformes; filete ereto Abuta obovata

4'. Lâmina foliar plana, venação actinódroma suprabasal.

6. Ápice foliar agudo ou acuminado; margem da lâmina foliar repanda; nervuras secundárias divergindo da região mediana ou distal; pedúnculo cilíndrico, estrigoso; estames conatos em grupos de 3; filete pubérulo; estigma inteiro ou lobado; drupas velutinas.....

Abuta brevifolia

6'. Ápice foliar atenuado ou cuspidado; margem da lâmina foliar retilínea; nervuras secundárias divergindo do terço inferior; pedúnculo tetragonal, seríceo; estames livres ou conatos apenas no ponto de inserção basal; filete glabro; estigma bífido; drupas glabras Abuta solimoesensis

1'. Arbustos.

7. Pecíolo glabro; lâmina foliar plana, glabra em ambas as faces; venação acródroma basal; brácteas glabras; antera com deiscência transversal ou colateral; ovário glabro a pubescente; estigma falciforme ou liguliforme, subapical...... .Abuta grandifolia

7'. Pecíolo estrigoso; lâmina foliar bulada, esparsamente pubescente na face adaxial e pubescente ou híspida na abaxial; venação actinódroma basal; brácteas estrigosas ou seríceas; antera com deiscência longitudinal; ovário seríceo; estigma acicular ou subulado, apical Abuta sandwithiana

1. Abuta barbata Miers, Contr. Bot. 3: 83. 1871.

Fig. 1a-d

Liana 1,5-26 cm diâm., escandente; ritidoma acinzentado, fissurado; alburno alaranjado. Pecíolo 6,5-7,5 cm compr., 0,25-0,3 cm diâm., cilíndrico, viloso-ferrugíneo. Lâmina foliar 7,2-27 cm compr., 8,9-16,5 cm larg., basifixa, elíptica, obovada ou suborbicular, cartácea, discolor, bulada, viloso-ferrugíneas em ambas as faces; ápice obtuso, arredondado ou emarginado; base inteira ou 2-lobada, obtusa ou emarginada; margem inteira, retilínea. Venação actinódroma basal, nervuras principais 3-palmatinérveas, impressas, 2-submarginais; nervuras secundárias divergindo do terço inferior laminar; nervuras terciárias escalariformes, impressas. Inflorescências em panículas, multifloras, axilares. Pedúnculo 0,2-3,1 cm compr., 0,5-1 mm diâm., cilíndrico, estrigoso. Brácteas 2-4,8 mm compr., 0,5-1 mm larg., lanceoladas ou oblongas, tomentosas ou vilosas. Flores estaminadas esverdeadas; sépalas 6 , dispostas em verticilo bisseriado, 0,6-2 $\mathrm{mm}$ compr., 0,2-1,7 mm larg., elípticas, ovaladas ou oblongas, tomentosas ou vilosas; estames livres ou pelo menos dois conatos, oblongos, clavados ou gibosos; filete curvado na região dorsal e/ou ventral, glabro; anteras com deiscência longitudinal. Flores pistiladas esverdeadas a amareladas; sépalas 6, dispostas em verticilo bisseriado, 0,4-2 mm compr., 0,25-2 mm larg., elípticas, ovaladas, obovadas ou oblongas, tomentosas; estaminódios $0,5-1$ mm compr., filiformes, glabros; ovário $0,7-1,4$ $\mathrm{mm}$ compr., giboso ou ovoide, piloso; estigma bífido, labiado ou liguliforme, subapical. Drupas 2-2,2 cm compr., 1,1-1,9 cm diâm., elipsoides ou subglobosas, esverdeadas, seríceas; ápice obtuso a arredondado; base obtusa ou assimétrica; epicarpo subcoriáceo a coriáceo, mesocarpo carnoso ou delgado; endocarpo lenhoso.

Material examinado: Rio Branco, Serra da Malacacheta, floresta de terra firme, VIII.1913, fl., J.G. Kulhmann 455 (NY, RB). 

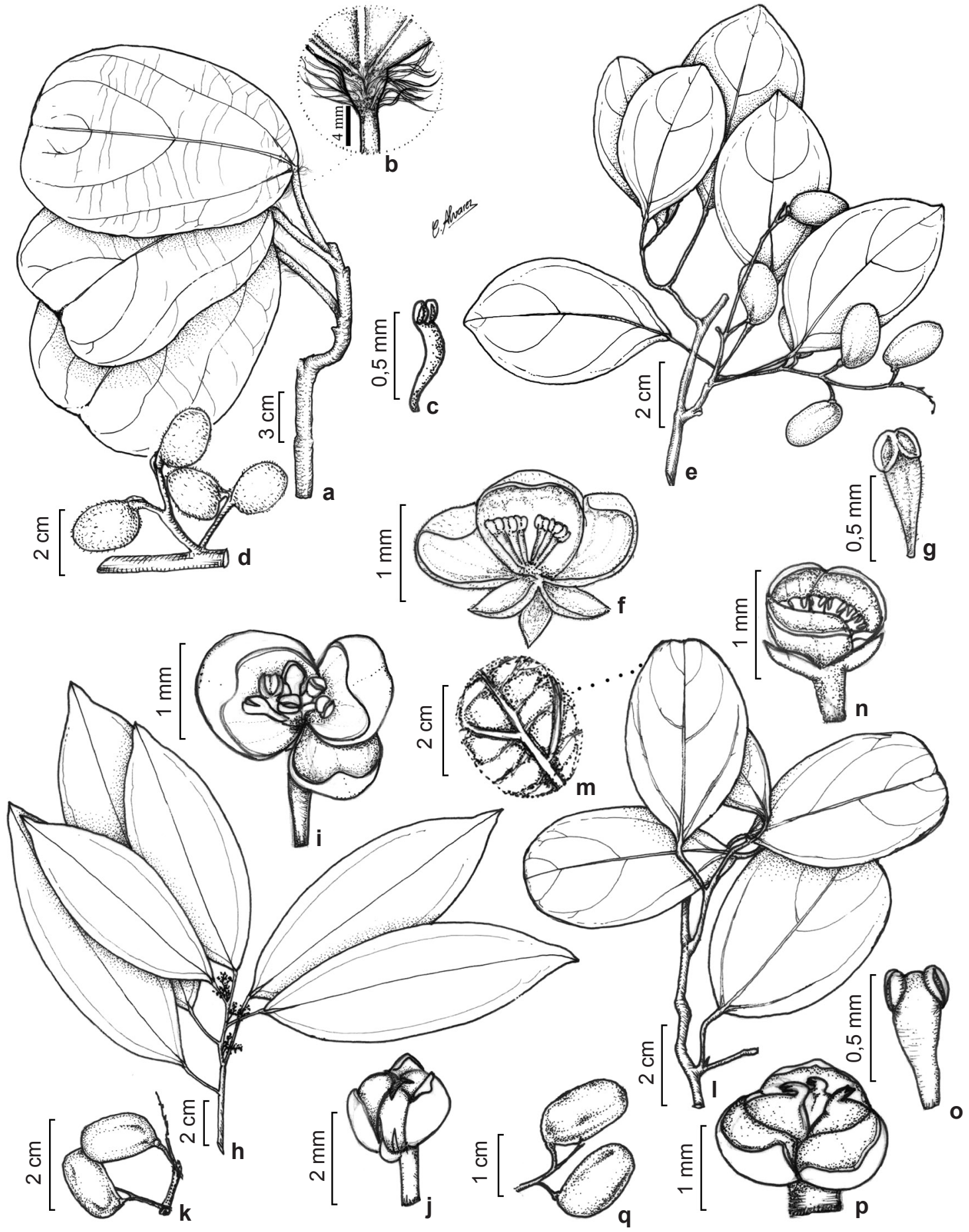

Figura 1 - a-d. Abuta barbata - a. ramo estéril; b. detalhe do indumento viloso no ápice do pecíolo; c. estame; d. detalhe do ramo com drupas. e-g. A. brevifolia - e. ramo com drupas; f. flor estaminada; g. estame. h-k. A. grandifolia - h. ramo com flores diminutas; i. flor estaminada; j. flor pistilada; k. fragmento de um ramo com drupas. 1-q. A. obovata-1. ramo estéril; $m$. detalhe da face adaxial; $n$. flor estaminada; o. estame; $p$. flor pistilada; q. fragmento de um ramo com drupas. Figure 1 - a-d. Abuta barbata - a. sterile branch; b. detail of villous indument on the apex of petiole; c. stamen; d. detail of branch with drupe. e-g. A. brevifolia - e. branch with drupe; f. staminate flower; g. stamen. h-k. A. grandifolia - h. branch with small flowers; i. staminate flower; j. pistillate flower; k. fragment of a branch with drupe. 1-q. A. obovata -1. sterile branch; m. detail of adaxial surface; n. staminate flower; o. stamen; p. pistillate flower; q. fragment of a branch with drupe. 
Material adicional: BRASIL. PARÁ: Altamira, travessão do CNEC, próximo à margem do Rio Xingu, floresta secundária de terra firme, 2.XII.1986, fr., S.A.M. Souza et al. 651 (MG); Jauarisinho, Rio Tocantins, floresta de terra firme, IX.1948, fl., R.L. Fróes 23451 (NY); 14.IX.1948, fl., R.L. Fróes 23459 (NY). Marapanim, floresta de terra firme, 15.XII.2011, fr., J.S. Sousa 518 (MG); Remansão, Rio Tocantins, 4.IX.1948, fl., R.L. Fróes 23382 (IAN, NY). VENEZUELA. Margem do Rio Orinoco, 9.I.1952, fl. e fr., J.M. Cruxent 280 (NY).

Distribuição: ocorre na Guiana, Suriname, Guiana Francesa e Brasil: Acre e Pará (BFG 2015; MBG 2016). O táxon pode ser encontrado em floresta de terra firme, em solos argilosos ou areno-argilosos (Sousa et al. 2014).

Entre os táxons de Abuta ocorrentes no estado do Acre, A. barbata é facilmente distinta das demais por ser a única a possuir indumentos viloso-ferrugíneos no pecíolo e em ambas as faces da lâmina foliar, filete curvado na região dorsal e/ ou ventral e drupas seríceas.

2. Abuta brevifolia Krukoff \& Moldenke, Bull. Torrey Bot. Club 69: 160. 1942. Fig. 1e-g

Liana 18-29 cm diâm., escandente; ritidoma marrom, fissurado; alburno creme. Pecíolo 7,1-30 mm compr., 0,9-1,4 mm diâm., cilíndrico, pubescente. Lâmina foliar 2,4-6,9 cm compr., 1,6-4,3 cm larg., basifixa, elíptica ou ovalada, coriácea, discolor, plana, glabra a esparsamente pubescente na face adaxial, pubescente na abaxial; ápice agudo ou acuminado; base inteira, cuneada ou obtusa; margem inteira, repanda. Venação actinódroma suprabasal, nervuras principais 3-plinérveas, superficiais a impressas; nervuras secundárias divergindo da região mediana ou distal; nervuras terciárias escalariformes, superficiais. Inflorescências em panículas, multifloras, axilares ou supra-axilares. Pedúnculo 1,7-3,9 cm compr., 0,4-1 mm diâm., cilíndrico, estrigoso. Brácteas 0,6-3,5 mm compr., 0,25-0,7 mm larg., deltoides ou ovaladas, estrigosas. Flores estaminadas amareladas; sépalas 6 , em verticilo bisseriado, 0,5-1,7 mm compr., 0,2-1,3 mm larg., deltoides, elípticas, orbiculares, obovadas ou oblongas, estrigosas; estames conatos em grupos de 3, clavados; filete ereto, pubérulo; anteras com deiscência longitudinal. Flores pistiladas amareloesbranquiçadas; sépalas 6 , dispostas em verticilo bisseriado, 0,5-1,9 $\mathrm{mm}$ compr., 0,25-1,5 mm larg., lanceoladas, deltoides, elípticas, orbiculares ou obovadas, tomentosas; estaminódios 0,5-1,4 mm compr., filiformes, glabros; ovário 0,5-1,5 $\mathrm{mm}$ compr.,ovoide, estrigoso; estigma inteiro ou lobado, falciforme ou labiado, subapical. Drupas 1,7-2,7 cm compr., 1-1,2 cm diâm., oblongoides, esverdeadas, velutinas; ápice obtuso a arredondado; base obtusa ou assimétrica; epicarpo subcoriáceo a coriáceo, mesocarpo carnoso ou delgado; endocarpo lenhoso.

Material examinado. Cruzeiro do Sul, Serra da Moa, floresta de terra firme, 19.IV.1971, fl., G.T. Prance et al. 12121 (MG, NY); Rio Moa, entre Cachoeira Grande e Serra da Moa, floresta de terra firme, 28.IV.1971, fl., G.T. Prance et al. 12615 (NY, R).

Material adicional: BRASIL. PARÁ: Moju, capoeira, 7.VII.2011, fl., J.S. Sousa 515 (MG); região do Jari, estrada entre Tinguelim e São Miguel, floresta de terra firme, 6.I.1971, fl., N.T. Silva 3432 (NY); Rio Cururú, floresta de terra firme, 18.II.1974, fl., W.R. Anderson 11075 (IAN, NY); Rod. Belém-Brasília, km 162-170, floresta de terra firme, 10.V.1960, fr., E. Oliveira 735 (IAN). Santa Bárbara, Parque Ecológico do Gunma, próximo ao km 50 da rodovia Augusto Meira Filho, floresta de terra firme, 5.X.2013, fl., J.S. Sousa 553 (MG). Tomé-Açu, estrada para a fazenda Borba Gato, 400 km do Rio Acará, floresta de terra firme, 4.XI.1979, fr., A. Pinheiro \& M.G. Silva 5129 (NY).

Distribuição: distribui-se na Venezuela e Brasil: Acre, Amazonas e Pará (BFG 2015; MBG 2016). De acordo com BFG (2015), a espécie pode ser encontrada em floresta de terra firme e campinarana. Através de observação de campo notou-se que a espécie tem preferência por florestas densas e fechadas de terra firme, sendo encontrada no interior da mesma, em solos argilosos ou arenosos.

A espécie aqui tratada mostrou-se nitidamente diferente das demais espécies de Abuta ocorrentes no Acre, sendo claramente reconhecida por apresentar menores folhas, estames conatos em grupos de 3 e filete pubérulo.

3. Abuta grandifolia (Mart.) Sandwith, Bull. Misc. Inform. Kew 1937: 397. $1937 . \quad$ Fig. 1h-k

Arbusto escandente 1,8-4 m. alt., 6-29 cm diâm.; ritidoma acinzentado, fissurado; alburno amarelo-esbranquiçado. Pecíolo 0,8-14,5 cm compr., 1-2,5 mm diâm., cilíndrico, glabro. Lâmina foliar 7,5-49 cm compr., 2,7-14,8 cm larg., basifixa, elíptica, elíptico-lanceolada ou oblonga, cartácea, discolor, plana, glabra em ambas as faces; ápice agudo ou acuminado; base inteira, cuneada ou obtusa; margem inteira, retilínea. Venação acródroma basal, nervuras principais 3-palmatinérveas, proeminentes; nervuras secundárias e terciárias divergindo do terço inferior laminar, inconspícuas na face adaxial. Inflorescências em bótrios, racemos simples ou 
panículas, multifloras, axilares, supra-axilares e/ ou caulifloras. Pedúnculo 3,5-9,2 cm compr., 1-2,2 mm diâm., cilíndrico, glabro. Brácteas 0,8-2,4 mm compr., 0,5-0,9 mm larg., ovaladas ou deltoides, glabras. Flores estaminadas amareloesbranquiçadas; sépalas 6 , dispostas em verticilo bisseriado, 0,5-2,8 mm compr., 0,25-1,6 mm larg., elípticas, ovaladas, orbiculares ou oblongas, pubérulas; estames livres ou conatos formando um sinândrio, clavados; filete ereto, glabro; anteras com deiscência transversal ou colateral. Flores pistiladas esverdeadas a amareladas; sépalas 6, dispostas em verticilo bisseriado, 0,5-2,6 mm compr., 0,3-2 mm larg., elípticas, lanceoladas, ovaladas, orbiculares ou oblongas, pubérulas; estaminódios 0,5-1,2 mm compr., lanceolados, glabros; ovário $0,6-1,5 \mathrm{~mm}$ compr., ovoide ou giboso, glabro a pubescente; estigma inteiro ou lobado, falciforme ou liguliforme, subapical. Drupas 1,5-2,9 cm compr., 0,6-1,2 cm diâm., oblongoides ou obovoides, amarelas à alaranjadas, glabras ou esparsamente pubescentes; ápice obtuso a arredondado; base obtusa ou assimétrica; epicarpo subcoriáceo, mesocarpo carnoso; endocarpo lenhoso.

Material examinado: Brasiléia, bacia do Rio Purus, acima do Rio Acre, 22.III.1998, fl., D.C. Daly et al. 9712 (NY). Bujari, bacia do Rio Purus, Riozinho do Andirá, floresta de várzea, 25.III.1995, fl., D.C. Daly et al. 8492 (NY). Cruzeiro do Sul, estrada Alemanha, floresta de terra firme, 8.V.1971, fl., P.J.M. Maas et al. P12781 (INPA, NY); próximo à Serra do Divisor, floresta de terra firme, 4.III.1976, fl., J. Ramos \& G. Mota 281 (INPA); reserva extrativista do alto Juruá, floresta de terra firme, 11.III.1992, fl. e fr., C.A. Cid et al. 10766 (INPA, NY). Feijó, bacia do Rio Muru, floresta sazonalmente inundada, 17.IV.2002, fl., P. Delprete et al. 8560 (NY). Plácido de Castro, Rio Abunã, floresta de terra firme, 22.III.2011, fl. e fr., R.C. Forzza et al. 6184 (RB). Rio Branco, bacia do Rio Purus, próximo ao riozinho do Rola, Piçarreira, floresta de terra firme, 15.III.1997, fl. \& fr., D.C. Daly et al. 9555 (NY); parque zoobotânico, floresta secundária de terra firme, 7.VI.1991, fl., A. Paula et al. 25 (INPA); área próxima ao projeto do herbário, floresta secundária de terra firme, 11.IX.1991, fl. e fr., C.A. Cid et al. 10238 (INPA, NY); Campus da Universidade Federal do Acre, próximo à trilha de acesso ao herbário, floresta de terra firme, 11.V.2011, fl., J.S. Sousa 513 (MG). Senador Guiomard, km 27 da BR-317, floresta de terra firme, 20.V.2009, fl., D.C. Daly et al. 13790 (RB).

Distribuição geográfica: ocorre na Venezuela, Bolívia, Colômbia, Equador, Guiana, Guiana Francesa, Peru, Suriname e Brasil: Acre, Amapá, Amazonas, Goiás, Maranhão, Mato Grosso, Mato Grosso do Sul, Pará, Rondônia, Roraima e
Tocantins (BFG 2015; MBG 2016; Sousa et al. 2014). A espécie é adaptada a diversos ambientes, podendo ser encontrada em áreas alagadas (floresta de várzea, floresta de igapó e floresta ripária), em floresta de terra firme, floresta ombrófila densa, floresta estacional semidecidual, savana, cerrado, restinga e floresta mista de transição; em condições de solos argilosos, areno-argilosos a lateríticos, contrastando com Barneby (2002), que relata a ocorrência da espécie em sub-bosques de florestas não inundadas.

Abuta grandifolia pode ser confundida com os espécimes de A. panurensis do Amazonas pela semelhança morfológica das folhas, porém a primeira diferencia-se por ser um arbusto escandente, apresentando folhas com venação acródroma basal, anteras com deiscência transversal ou colateral, estaminódios lanceolados e estigma inteiro, enquanto a segunda é uma liana com venação acródroma suprabasal, anteras com deiscência longitudinal, estaminódios filiformes ou oblongos e estigma bífido. $\mathrm{Na}$ área de estudo, a espécie é facilmente reconhecida por ser a única que possui venação acródroma basal e anteras com deiscência transversal ou colateral.

4. Abuta obovata Diels, Notizbl. Bot. Gart. BerlinDahlem 13: 20. 1936.

Fig. 11-q

Liana 11-29 cm diâm.; ritidoma marrom a acinzentado, profundamente sulcado; alburno creme a alaranjado. Pecíolo 0,7-2,9 cm compr., 0,9-1,5 mm diâm., cilíndrico, pubescente. Lâmina foliar 3,8-9 cm compr., 2,5-7,8 cm larg., basifixa, obovada, coriácea, concolor à sutilmente discolor, profundamente bulada, pubescente em ambas as faces; ápice obtuso, arredondado ou emarginado; base inteira, cuneada, obtusa ou assimétrica; margem inteira, retilínea. Venação actinódroma basal; nervuras principais 3-palmatinérveas, profundamente impressas; nervuras secundárias divergindo da região mediana até o terço superior, impressas; nervuras terciárias escalariformes, superficiais ou proeminentes na face adaxial. Inflorescências em racemos compostos fasciculados ou em panículas, multifloras, axilares ou supraaxilares. Pedúnculos 1-2,3 cm compr., 0,5-0,7 $\mathrm{mm}$ diâm., cilíndrico, estrigoso. Brácteas 0,5-0,9 $\mathrm{mm}$ compr., 0,5-0,9 $\mathrm{mm}$ larg., ovaladas ou cimbiformes, tomentosas. Flores estaminadas, esverdeadas; sépalas 6-9, dispostas em verticilo bisseriado ou trisseriado, $0,26-1 \mathrm{~mm}$ compr., 0,25-0,9 mm larg., elípticas, ovaladas, obovadas ou orbiculares, estrigosas ou tomentosas; estames 
parcialmente conatos, formando um sinândrio obcônico, dolabriformes ou gibosos; filete ereto, glabro; anteras com deiscência longitudinal. Flores pistiladas esverdeadas; sépalas 6-9, dispostas em verticilo trisseriado, 0,5-1,3 mm compr., 0,25-1,4 $\mathrm{mm}$ larg., deltoides, obovadas ou orbiculares, estrigosas a tomentosas; estaminódios 0,8-1,5 mm compr., filiformes, glabros; ovário 1-2 mm compr., ovoide a giboso, seríceo ou tomentoso; estigma bífido, labiado, subapical. Drupas 1,3-2 cm compr., 0,6-1,3 cm diâm, oblongoides, obovoides ou subglobosas, estipitadas, esverdeadas, tomentosas; ápice obtuso a arredondado; base cuneada, obtusa ou assimétrica; epicarpo subcoriáceo a coriáceo, mesocarpo delgado; endocarpo lenhoso.

Material examinado: Serra do Moa, Rio Moa, 6 km, floresta de várzea, 25.IV.1971, fl., G.T. Prance et al. 12437 (INPA, NY, R).

Material adicional: BRASIL. AMAZONAS: Manaus, comunidade de Tunuí, perto do igarapé Jacitarí, 18.VIII.2008, fr., P. Acevedo-Rdgz. et al. 14636 (INPA); Reserva Florestal Adolpho Ducke, campinarana, 30.VII.2013, fl., J.S. Sousa 543 (MG). Presidente Figueiredo, margem do Rio Uatumã, entre a foz do Rio Pitinga e o igarapé Arraia, 19.III.1986, fl., C.A. Cid et al. 6857 (INPA, NY). São Gabriel da Cachoeira, floresta de terra firme, 15.XI.1941, fl., R.L. Fróes 12379 (NY). PARÁ: Barcarena, capoeira, 14.IV.2011, fl. e fr., J.S. Sousa 507 (MG). Oriximiná, próximo à Estação Ecológica Grão Pará, floresta de terra firme, 21.XII.2012, fl., Sousa J.S. 533 (MG).

Distribuição geográfica: Abuta obovata distribui-se na Venezuela, Guiana, Guiana Francesa, Peru, Suriname e Brasil: Acre, Amazonas, Amapá, Rondônia e Pará (BFG 2015; MBG 2016; Sousa et al. 2014b). A espécie é frequentemente encontrada em floresta de terra firme, podendo ocorrer também em ambientes alagados (florestas de várzea, de igapó e ripária), em solos argilosos ou arenoargilosos e também em campinarana, conforme relatado por Sothers et al. (1999).

Vários espécimes de Abuta obovata analisados estavam identificados como $A$. brevifolia devido à semelhança morfológica das folhas, principalmente pelos padrões de venação, conforme salientado por Sousa et al. (2014b). Porém, podem ser diferenciados por caracteres vegetativos, uma vez que $A$. obovata possui lâmina foliar obovada, face adaxial bulada e nervuras principais 3-palmatinérveas na base, enquanto que $A$. brevifolia possui lâmina foliar elíptica à ovalada, face adaxial plana e nervuras principais 3-plinérveas na base. Entre as cogenéricas, $A$. obovata é claramente identificável pela lâmina foliar obovada, profundamente bulada.
5. Abuta pahnii (Mart.) Krukoff \& Barneby, Mem. New York Bot. Gard. 22(2): 43-45. 1971.

Fig. 2a-d

Liana 20-35 cm diâm., escandente; ritidoma vináceo, sulcado; alburno avermelhado. Pecíolo 4,5-5,7 cm compr., 0,1-0,2 cm diâm., cilíndrico, tomentoso. Lâmina foliar 8,2-11,9 cm compr., 5,7-9,5 cm larg., basifixa, elíptica ou suborbicular, coriácea, concolor à inconspicuamente discolor, bulada, hirsuta; ápice acuminado, agudo ou obtuso; base inteira, cuneada, obtusa ou arredondada; margem inteira, retilínea à repanda. Venação actinódroma basal, nervuras principais 5-palmatinérveas, impressas; nervuras secundárias divergindo da região proximal ou da mediana; nervuras terciárias escalariformes, impressas. Inflorescências em bótrios, racemos simples ou panículas, multifloras, supra-axilares. Pedúnculo 0,25-1,4 cm compr., 0,5-0,7 mm diâm., cilíndrico, tomentoso. Brácteas 1,6-3,7 mm compr., 0,9-1,6 $\mathrm{mm}$ larg., falcadas ou lanceoladas, seríceas ou lanosas. Flores estaminadas esverdeadas; sépalas 6 , dispostas em verticilo bisseriado, 0,4-1 mm compr., 0,25-0,9 mm larg., elípticas, lanceoladas, obovadas ou orbiculares, lanosas ou seríceas; estames conatos apenas no ponto de inserção basal, clavados; filete ereto, glabro; anteras com deiscência longitudinal. Flores pistiladas esverdeadas; sépalas 6, dispostas em verticilo bisseriado; 0,3-1,1 mm compr., 0,25-1 mm larg., cimbiformes, elípticas, deltoides ou orbiculares, lanosas ou seríceas; estaminódios 0,7-1 mm compr., filiformes, glabros; ovário 0,6-1 mm compr., ovoide a turbinado, lanoso ou seríceo; estigma bífido, liguliforme, subapical. Drupas 1,1-2,1 cm compr., 0,5-1,5 cm diâm., oblongoides ou obovoides, esverdeadas, lanosas; ápice obtuso a arredondado; base cuneada, obtusa ou assimétrica; epicarpo coriáceo, mesocarpo delgado; endocarpo lenhoso.

Material examinado: Sena Madureira, próximo à entrada do Rio Macauã, afluente do Rio Iaco, floresta de terra firme, 11.VIII.1933, fr., B.A. Krukoff 5437 (NY). Material adicional: BRASIL. AMAZONAS: Borba, próximo a Bela Vista, floresta de terra firme, 4-6.IX.1934, fl., B.A. Krukoff 5978 (NY). MATO GROSSO: Aripuanã, às margens do Rio Aripuanã, acima da Cachoeira das Andorinhas, floresta de terra firme, 19.X.1973, fl., C.C. Berg P18681 (NY). Sinop, Fazenda Atlântica, floresta de terra firme, 25.IX.1985, fl., W. Thomas et al. 4043 (MG, NY). RONDÔNIA: Porto Velho, na estrada para a área de mineração no Balateiro, floresta de terra firme, 23.IV.1987, fl., M. Nee 34991 (INPA, NY).

Distribuição: distribui-se na Venezuela, Colômbia, Equador, Peru e Brasil: ocorrendo nos 


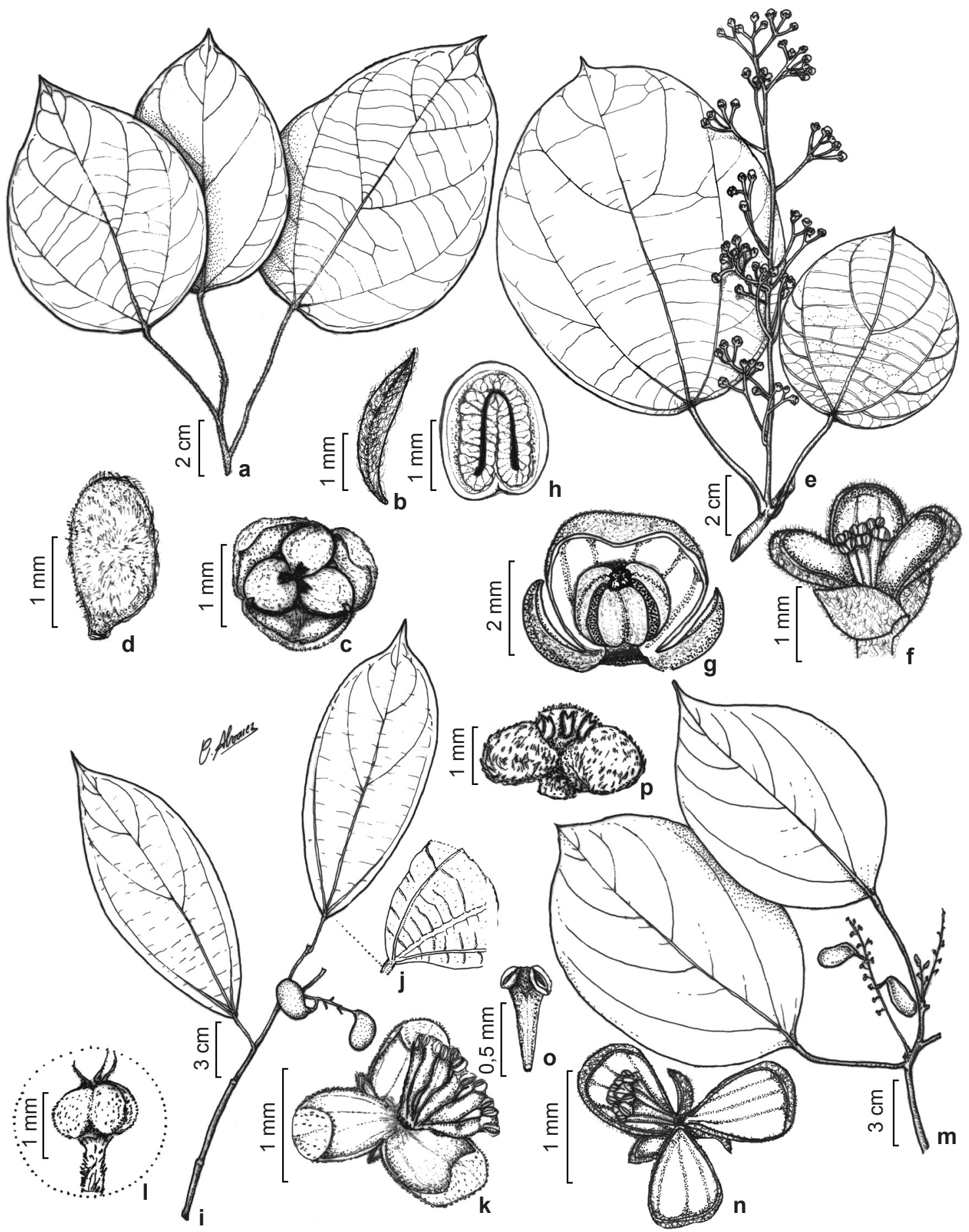

Figura 2 - a-d. Abuta pahnii - a. ramo estéril; b. bráctea; c. vista frontal da flor pistilada; d. drupa. e-h. A. rufescens - e. ramo florífero; f. flor estaminada; g. vista lateral da flor pistilada com três sépalas removidas; h. drupa em secção longitudinal. i-1. A. sandwithiana - i. ramo com drupas; j. base foliar em detalhe; k. flor estaminada; 1 . gineceu. $\mathrm{m}-\mathrm{p}$. A. solimoesensis - m. ramo com flores e frutos; $n$. flor estaminada; o. estame; p. gineceu.

Figure 2 - a-d. Abuta pahnii - a. sterile branch; b. bract; c. front view of pistillate flower; d. drupe. e-h. A. rufescens - e. branch; f. staminate flower; g. side view of pistillate flower with three sepals removed; h. drupe in longitudinal section. i-l. A. sandwithiana - i. branch with drupe; j. leaf base in detail; k. staminate flower; 1. gynoecium. m-p. A. solimoesensis $-\mathrm{m}$. branch with flowers and fruits; n. staminate flower; o. stamen; p. gynoecium. 
estados do Acre, Amazonas, Rondônia e Mato Grosso (BFG 2015; MBG 2016). Segundo Ortiz (1997), pode ser encontrada em bosques primários e ambientes com deficiência de drenagem, porém, no Brasil, pode ocorrer também em florestas de terra firme e de várzea, em solos areno-argilosos.

De acordo com Ortiz (1997), Abuta pahnii pode apresentar lâmina foliar oblonga a suborbicular, entretanto, no material examinado as folhas variaram de elípticas a suborbiculares corroborando o estudo realizado por Sousa et al. (2014b).

Quando estéril, Abuta pahnii é comumente confundida com A. rufescens pelos caracteres foliares, no entanto pode diferenciar-se desta última por possuir ritidoma vináceo, indumentos hirsutos na lâmina foliar, brácteas falcadas ou lanceoladas e drupas oblongoides ou obovoides, enquanto $A$. rufescens apresenta ritidoma marrom-escuro a acinzentado, indumentos tomentosos em ambas as faces da folha, brácteas ovaladas ou orbiculares e drupas subglobosas.

6. Abuta rufescens Aubl., Hist. P1. Guiane 1: 618620 , t. 250.1775.

Fig. 2e-h

Liana 7-27 cm diâm., escandente; ritidoma marrom a acinzentado, fissurado; alburno creme. Pecíolo 1,5-17 cm compr., 0,1-0,28 cm diâm., cilíndrico, tomentoso. Lâmina foliar $4-24,8 \mathrm{~cm}$ compr., 3,6-24,8 cm larg., basifixa ou subpeltada, cordiforme, ovalada ou suborbicular, cartácea a coriácea, discolor, bulada, cinéreo-tomentosa nas nervuras na face adaxial, cinéreo-tomentosa na abaxial; ápice agudo, acuminado ou retuso; base inteira ou bilobada, arredondada, emarginada ou cordada; margem inteira, repanda ou retilínea. Venação actinódroma basal; nervuras principais 5-palmatinérveas, impressas; nervuras secundárias divergindo da região mediana ou da região proximal; nervuras terciárias escalariformes, impressas. Inflorescências em bótrios, racemos simples, racemos compostos fasciculados ou panículas, multifloras, axilares ou supra-axilares. Pedúnculo 0,25-2,5 cm compr., cilíndrico, velutino. Brácteas 0,9-1,5 mm compr., 0,6-1 mm larg., ovaladas, tomentosas ou velutinas. Flores estaminadas esverdeadas; sépalas 6-9, em verticilo trisseriado, 0,6-3,9 mm compr., 0,5-3,9 mm larg., obovadas, ovaladas ou orbiculares, velutinas; estames livres ou conatos apenas no ponto de inserção basal, formando um sinândrio, oblongos, clavados ou turbinados; filete ereto, glabro ou papiloso; anteras com deiscência longitudinal. Flores pistiladas esverdeadas a esbranquiçadas; sépalas
6-9, dispostas em verticilo trisseriado, 0,6-4,2 $\mathrm{mm}$ compr., 0,5-4 mm larg., deltoides, elípticas, ovaladas ou orbiculares, velutinas; estaminódios 1,5-3 mm compr., falciformes, pubescente na região dorsal; ovário 1,7-3 mm compr., ovoide a turbinado, velutino; estigma lobado, labiado, subapical. Drupas 1,8-2,1 cm compr., 1,6-1,9 cm larg., subglobosas, esverdeadas, velutinas ou tomentosas; ápice obtuso a arredondado; base cuneada, obtusa ou assimétrica; epicarpo subcoriáceo a coriáceo, mesocarpo carnoso; endocarpo lenhoso.

Material examinado: Rio Branco, base Euclides da Cunha, 6.IV.1948, R.L. Fróes 23181 (NY). Sena Madureira, Floresta Estadual do Antymari, ca. $30 \mathrm{~km}$ da sede Uirapuru, 3.IX.2013, fr., H. Medeiros et al. 1091 (RB).

Material adicional: BRASIL. PARÁ: Belém, Utinga, 20.XI.1945, fl., J.M. Pires \& G.A. Black 661 (IAN, NY). Marabá, Serra dos Carajás, 29.III.1977, fl., M.G. Silva \& R. Bahia 2932 (IAN, NY). Marituba, companhia da Pirelli, Fazenda Uriboca, floresta de terra firme, VII.1958., fl., J.M. Pires 7002 (IAN). Monte Dourado, floresta de terra firme, 19.VII.2012, fr., J.S. Sousa 530 (MG). Oriximiná, adjacente à Estação Ecológica Grão Pará, floresta de terra firme, 22.XII.2012, fl., J.S. Sousa 535 (MG); região do Jarí, Monte Dourado, floresta de terra firme, 21.X.1968, fl., N.T. Silva 1282 (IAN, NY); Santa Bárbara, Parque Ecológico de Gunma, floresta de terra firme, 23.V.2012, fr., J.S. Sousa 528 (MG). Santa Bárbara, Parque Ecológico de Gunma, floresta de várzea, 5.X.2013, fr., J.S. Sousa 554 (MG).

Distribuição geográfica: Abuta rufescens distribui-se na Venezuela, Colômbia, Equador, Guiana, Guiana Francesa, Peru, Suriname e Brasil: Acre, Amapá, Amazonas, Pará, Rondônia, Roraima, Tocantins (BFG 2015; MBG 2016). De acordo com Barneby (2001), A. rufescens ocorre em florestas primárias não inundáveis, floresta de galeria e savanas. No Brasil, a espécie é comumente encontrada em floresta de terra firme, mas também pode ocorrer em restinga, floresta de várzea e floresta ripária; em solos argilosos, arenosos ou areno-argilosos.

A espécie requer cuidado ao analisá-la, principalmente quando os espécimes são jovens, pois nessa fase as formas das folhas e dos estames variam bastante, podendo ser confundida com Abuta parhnii e A. grisebachii. Quando A. rufescens apresenta a lâmina foliar cordiforme e a base foliar bilobada, pode ser facilmente distinguida das duas espécies acima citadas, caso contrário, o conjunto de caracteres formado pela face abaxial cinéreotomentosa, estames inconspicuamente papilosos e a drupa subglobosa ajudarão na separação da espécie em relação às outras, já mencionadas. 
Entre as espécies estudadas, A. rufescens é a única que possui lâmina foliar cinéreo-tomentosa; estaminódios falciformes, pubescente na região dorsal, bem como pedúnculo e ovário velutinos.

7. Abuta sandwithiana Krukoff \& Barneby, Mem. New York Bot. Gard. 20(2): 18. $1970 . \quad$ Fig. 2i-1

Arbusto escandente 1,8-5 m alt., 25-32 cm diâm., ritidoma acinzentado, fissurado; alburno amarelo. Pecíolo 0,9-5,1 cm compr., 0,1-0,2 cm diâm., cilíndrico, estrigoso. Lâmina foliar 3,4-19 cm compr., 1,9-8,7 cm larg., basifixa, elíptica ou oblongo-lanceolada, cartácea, concolor, bulada, esparsamente pubescente na face adaxial e pubescente ou híspida na abaxial; ápice acuminado ou atenuado; base inteira, cuneada ou obtusa; margem inteira, retilínea. Venação actinódroma basal, nervuras principais 3-palmatinérveas, profundamente impressas; nervuras secundárias divergindo do terço inferior ou da região mediana; nervuras terciárias escalariformes, impressas na face adaxial. Inflorescências em panículas ou racemos simples, multifloras, axilares. Pedúnculo $0,4-1 \mathrm{~cm}$ compr., cilíndrico, fissurado, estrigoso. Brácteas 0,7-2 mm compr., 0,6-0,9 $\mathrm{mm}$ larg., deltoides ou lanceoladas, estrigosas ou seríceas. Flores estaminadas esverdeadas; sépalas 6 , dispostas em verticilo bisseriado, 0,6-2,2 $\mathrm{mm}$ compr., 0,25-2 $\mathrm{mm}$ larg., deltoides, elípticas, oblanceoladas ou orbiculares, estrigosas; estames livres ou conatos apenas no ponto de inserção basal, obclavados, ou gibosos; filete ereto ou levemente curvado na região distal, glabro; anteras com deiscência longitudinal. Flores pistiladas esverdeadas; sépalas 6 , dispostas em verticilo bisseriado, 0,7-2,4 mm compr., 0,2-2,4 mm larg., deltoides, elípticas, oblanceoladas, ovaladas ou orbiculares, estrigosas; estaminódios 0,6-2,4 mm compr., lineares, glabros; ovário 0,6-2 mm compr., ovoide ou botuliforme, seríceo; estigma inteiro, acicular ou subulado, apical. Drupas 1,5-2,5 cm compr., 0,9-1,5 cm diâm., oblongoides ou elipsoides, esverdeadobrancacentas quando imaturas, amareladas à alaranjadas maduras, tomentosas; ápice obtuso a arredondado; base cuneada, obtusa ou assimétrica; epicarpo subcoriáceo a coriáceo, mesocarpo delgado; endocarpo lenhoso.

Material examinado: Cruzeiro do Sul, circunvizinhança da serra do Moa, floresta de várzea, 26.IV.1971, fr., G.T. Prance et al. 12461 (IAN, INPA).

Material adicional: BRASIL. MATO GROSSO: Aripuanã, km 245 da BR-174, núcleo de Juína, floresta de terra firme, 10.I.1979, fl., M.G. Silva \& A. Pinheiro 4216 (MG); bacia do Rio Juruena, fonteira com os estados do
Amazonas e Pará, 31.XII.1951, fl., Pires 3693 (NY). Novo Mundo, Parque Estadual Cristalino, 6.II.2008, fl. e fr., D. Zappi et al. 1056 (HERBAM; MG). PARÁ: Oriximiná, área da Estação Ecológica Grão Pará, floresta de terra firme, 22.XII.2012, fl., J.S. Sousa 534 (MG). Santa Bárbara, Parque Ecológico de Gunma, floresta de terra firme, 23.V.2012, fr., J.S. Sousa 529 (MG); 5.X.2013, fr., J.S. Sousa 551 (MG).

Distribuição geográfica: distribui-se na Bolívia, Guiana, Guiana Francesa, Peru, Suriname e Brasil: Acre, Amapá, Amazonas, Mato Grosso, Pará e Rondônia (BFG 2015; MBG 2016). Trata-se de uma espécie bastante adaptada aos ambientes de terra firme e áreas inundáveis (florestas de várzea e floresta ripária), ocorrendo em solos argilosos ou areno-argilosos (Sousa et al. 2014a).

Entre as cogenéricas estudadas, apenas Abuta sandwithiana e A. grandifolia possuem hábito do tipo arbusto escandente, porém a primeira espécie é facilmente distinguível, principalmente por apresentar lâmina foliar bulada, venação actinódroma basal, antera com deiscência longitudinal e estigma acicular ou subulado, enquanto a segunda espécie possui lâmina foliar plana, venação acródroma basal, antera com deiscência transversal ou colateral e estigma falciforme ou liguliforme.

8. Abuta solimoesensis Krukoff \& Barneby, Mem. New York Bot. Gard. 20(2): 18. 1970. Fig. 2m-p

Liana 22-28 cm diâm., escandente; ritidoma marrom, fissurado; alburno alaranjado. Pecíolo 2,9-7,7 cm compr., 0,1-0,2 cm diâm., cilíndrico, glabro a esparsamente pubescente. Lâmina foliar 5,3-20,9 cm compr., 4,2-12,9 cm larg., basifixa, elíptica ou ovalada, cartácea a coriácea, concolor, plana, glabra em ambas as faces; ápice atenuado ou cuspidado; base inteira, obtusa à arredondada; margem inteira, retilínea. Venação actinódroma suprabasal; nervuras principais 3-plinérveas, impressas e, quando presente, 2 submarginais; nervuras secundárias divergindo do terço inferior; nervuras terciárias escalariformes, superficiais. Inflorescências em panículas, multifloras, axilares ou supra-axilares. Pedúnculo 3-8 $\mathrm{mm}$ compr., tetragonal, seríceo. Brácteas 0,6-1,4 mm compr., 0,25-0,7 mm larg., deltoides ou lanceoladas, seríceas. Flores estaminadas esverdeadas; sépalas 6-9, dispostas em verticilo bisseriado ou trisseriado, 0,25-1,4 mm compr., 0,2-1 mm larg., deltoides, elípticas, lanceoladas, ovaladas ou orbiculares, estrigosas apenas na superfície externa; estames livres ou conatos apenas no ponto de inserção basal, clavados; filete ereto, glabro; anteras 
com deiscência longitudinal. Flores pistiladas esverdeadas; sépalas 6, dispostas em verticilo bisseriado, 0,2-1,9 mm compr., 0,25-1,7 mm larg., cimbiformes, deltoides, obovadas, ou orbiculares, estrigosas; estaminódios 0,9-1,5 mm compr., clavados ou lineares, glabros; ovário 0,7-1,3 mm compr., ovoide, turbinado ou botuliforme, tomentoso; estigma bífido, liguliforme, subapical. Drupas 1,7-2,3 cm compr., 0,7-1,3 cm larg., oblongoides, amareladas, glabras; ápice obtuso a arredondado; base obtusa ou assimétrica; epicarpo subcoriáceo a coriáceo, mesocarpo delgado; endocarpo lenhoso.

Material examinado: Cruzeiro do Sul, bacia do Rio Juruá-Mirim, floresta de terra firme, 14.V.2003, fr., D.C. Daly et al. 11807 (MO, NY ); 31.V.1994, M. Silveira 758 (UFACPZ).

Material adicional: BRASIL. AMAZONAS: Manaus, Reserva Florestal Adolpho Ducke, floresta de vertente, 30.VII.2013, fl., J.S. Sousa 544 (MG). Tefé, Lago Tefé, floresta de várzea, 24.VIII.1973, fl., E. Lleras et al. 17487 (NY). PARÁ: Belém, área do Instituto Agronômico do Norte, floresta de terra firme, 18.VIII.1964, fl. e fr., G.T. Prance \& N.T. Silva 58755 (UB). Castanhal, capoeira, 15.IV.2011, fl., J.S. Sousa 510 (MG).

Distribuição: distribui-se no Equador, Guiana Francesa, Peru e Brasil: Acre, Amazonas, Pará e Maranhão (BFG 2015; MBG 2016). Trata-se de uma espécie pouco frequente nas formações vegetais brasileiras, encontrada em florestas de terra firme e de várzea, em solos argilosos ou areno-argilosos.

Nas amostras de Abuta solimoesensis analisadas foi observada a forma foliar semelhante à de $A$. imene, no entanto, pode-se diferenciá-las pela disposição da nervura secundária, uma vez que em $A$. solimoesensis a nervura secundária diverge do terço inferior da lâmina foliar, enquanto em $A$. imene diverge a partir da região mediana do limbo. Além da diferença vegetativa entre as referidas espécies, a forma tetragonal do pedúnculo e ovário ovoide, turbinado ou botuliforme de $A$. solimoesensis são caracteres reprodutivos seguros para separá-la de $A$. imene, a qual apresenta pedúnculo cilíndrico e ovário obovoide.

\section{Agradecimentos}

Os autores agradecem ao Museu Paraense Emílio Goeldi e ao Conselho Nacional de Desenvolvimento Científico e Tecnológico (CNPq), a concessão da bolsa do Programa de Capacitação Institucional (PCI-MPEG) ao primeiro autor, e apoio logístico para a realização deste trabalho.

\section{Referências}

Albuquerque BWP (1972) Contribuição ao estudo da nervação foliar de plantas da flora amazônica. Acta Amazonica 34: 21-27.

Barneby RC (2001) Menispermaceae. In: Berry PE, Yatskievych K \& Host BK (eds.) Flora of the Venezuelan Guayana: Liliaceae-Myrsinaceae. Vol. 6. Missouri Botanical Garden, St. Louis. Pp. 554-578.

Barneby RC \& Krukoff BA (1971) Supplementary notes on American Menispermaceae. VIII. A generic survey of the American Triclisieae and Anomospermeae. Memoirs of the New York Botanical Garden 22: 1-89.

BFG - The Brazil Flora Group (2015) Growing knowledge: an overview of seed plant diversity in Brazil. Rodriguésia 66: 1085-1113.

Barroso GM, Morim MP, Peixoto AL \& Ichaso CLF (1999) Frutos e sementes: morfologia aplicada à sistemática de dicotiledôneas. Universidade Federal de Viçosa, Viçosa. 443p.

Di Stasi LC \& Hiruma-Lima CA (2002) Plantas medicinais na Amazônia e na mata Atlântica. UNESP, São Paulo. 64p.

Diels L (1910) Menispermaceae. In: Engler, A (ed.) Das Pflanzenreich 94: 1-345.

Fidalgo O \& Bononi VLR (1984) Técnicas de coleta, preservação e herborização do material botânico. Instituto de Botânica, São Paulo. 62p.

Harris JG \& Harris MW (2001) Plant identification terminology, an illustrated glossary. Spring Lake Publishing, Spring Lake. 216p.

Hickey LJ (1973) Classification of the arquitecture of dicotyledonous leaves. American Journal of Botany 60: 17-33.

Jacques FMB, Gallut C, Vignes-Lebbe R, Bagils RZ (2007) Resolving phylogenetic reconstruction in Menispermaceae (Ranunculales) using fossils and a novel statistical test. Taxon 56: 379-392.

Krukoff BA \& Barneby RC (1970) Supplementary notes on American Menispermaceae. VI. Memoirs of the New York Botanic Garden 20: 1-70.

Krukoff BA \& Moldenke HN (1938) Studies of American Menispermaceae, with special reference to species used in preparation of arrow-poisons. Brittonia 3: 1-74.

Ortiz R (1997) Menispermaceae. In: Vásquez MR (ed.) Flora de las Reservas Biológicas de Iquitos, Peru: monographs in systematic botany from the Missouri Botanical Garden. Vol. 63. Missouri Botanical Garden Press, St. Louis. Pp. 487-500.

Ortiz R (2011) Menispermaceae. Flora Mesoamericana. Disponível em $<$ http://www.tropicos.org/docs/meso/ menispermaceae.pdf $>$. Acesso em 6 maio 2016.

Missouri Botanical Garden - MBG (2016) Tropicos database. Disponível em $<$ http://www.tropicos.org $>$. Acesso em 5 maio 2016. 
Radford AE, Dickison WC \& Massey JR (1974) Vascular plant systematics. Harper \& Row, New York. 891p.

Rizzini CT (1977) Sistematização terminológica da folha. Rodriguésia 29: 103-125.

Sothers CA, Brito JM, Ortiz-Gentry R \& Ott C (1999) Menispermaceae. In: Ribeiro JELS et al. (eds.) Flora da Reserva Ducke: guia de identificação das plantas vasculares de uma floresta de terra-firme na Amazônia central. INPA, Manaus. 816p.

Sousa JS, Bastos MNC \& Gurgel ESC (2014a) Estudo taxonômico do gênero Abuta (Menispermaceae) no estado do Pará, Brasil. Acta Amazonica 44: 175-184.
Sousa JS, Bastos MNC \& Gurgel ESC (2014b) Taxonomia do gênero Abuta Aubl. (Menispermaceae) no estado de Rondônia, Brasil. Biota Amazônia 4: 62-72.

Thiers B [continuamente atualizado] Index herbariorum: a global directory of herbaria and associated staff. New York Botanical Garden's Virtual Herbarium. Disponível em $<$ http://sweetgum.nybg.org/science/ ih/>. Acesso em 28 novembro 2016.

Weberling F (1992) Morphology of flowers and inflorescences. Univeristy Press, New York. 405p.

Wefferling K, Hoot SB \& Neves SS (2013) Phylogeny and fruit evolution in Menispermaceae. American Journal of Botany 100: 1-23. 